\title{
Design of PI and Fuzzy Logic Controllers for Distribution Static Compensator
}

\author{
S.R.Reddy ${ }^{1}$, P.V.Prasad ${ }^{2}$, G.N.Srinivas ${ }^{3}$ \\ ${ }^{1}$ EEE Department, GNITC, Ibrahimpatnam, Hyderabad, India \\ ${ }^{2}$ Department EEE Department, CBIT, Gandipet, Hyderabad, India \\ ${ }^{3}$ Department EEE Department, JNTUH, Hyderabad, India
}

\begin{tabular}{l} 
Article Info \\
\hline Article history: \\
Received Dec 24, 2017 \\
Revised Jan 9, 2018 \\
Accepted Jan 23, 2018 \\
\hline Keyword: \\
Fuzzy logic controller \\
Harmonic compensation \\
Hysteresis current controller \\
Maximum distribution static \\
compensator (D-STATCOM) \\
PI controller \\
Synchronous reference frame \\
(SRF) theory
\end{tabular}

(SRF) theory

\begin{abstract}
This paper presents study of distribution static compensator (D-STATCOM) for compensation of reactive power, harmonic distortion mitigation and load balancing in three phase three wire nonlinear load distribution system. The proposed control algorithm is developed based on synchronous reference frame theory using PI and FUZZY logic controller. The obtained reference current signal from control algorithm is compared in hysteresis band current controller for better switching of D-STATCOM. The performance of DSTATCOM with PI and fuzzy logic controller is also analysed and compared for DC voltage regulation and harmonic distortion mitigation .The proposed method is provided effective compensation for reactive power, harmonic distortion mitigation and load voltage balancing. The simulation results are obtained using MATLAB/SIMULINK soft ware.
\end{abstract}

Copyright $(2018$ Institute of Advanced Engineering and Science. All rights reserved.

\section{Corresponding Author:}

S.R.Reddy, EEE Department, GNITC, Ibrahimpatnam, Hyderabad, India

Email: sadurajender@gmail.com

\section{INTRODUCTION}

In last one decade, power electronic devices are widely used in industrial applications for transferring power in more efficient way [1]. The excessive use of power electronic equipments, which represent nonlinear loads, in a distribution network has caused many disturbances in the quality of power such as harmonic pollutions, unbalanced load currents, and reactive power problems [2]. As a result poor power factor, weakening efficiency, overheating of motors and transformers, malfunction of sensitive devices etc [3-4]. Next power quality problem is unbalancing the source voltage due to unbalanced load. The un balanced source voltage may generate the lower order harmonic component in the power system and also cause a negative sequence current and torque reduction in case of electric machine drive system[5-8] These power quality problems also appear due to plenty of industrial products and equipments containing nonlinear loads [9].These power quality problems are compensated using custom power devices such as distribution static compensators (DSTATCOM), dynamic voltage restorer (DVR) and unified power quality conditioner (UPQC) [10].In which the distribution static compensator is more suitable for reactive power compensation, harmonic mitigation, load unbalancing voltage variations and current harmonics in the distribution network compared to other custom power devices[11]. The SRF control scheme need PI controller for regulating DClink voltage. The PI controller need precise mathematical model values which will be tough to get and it may not give suitable results under parameter variation, load variations etc [12-14]. The implementation of fuzzy logic controller for DSTATCOM has a great deal of attention. The advantages of fuzzy logic controller over 
PI controller are it doesn't require accurate mathematical model values and it can handle any non linearity with inaccurate inputs values. Mostly mamdani type fuzzy logic controller is used and it gives better results for SRF controlled DSTATCOM. The fuzzy logic controller gives better results for DSTATCOM application while comparing with PI controller $[15,16]$.

In this paper SRF controlled DSTATCOM is proposed and implemented on $11 / 0.4 \mathrm{kv}$ distribution system. The performance of the proposed DSTATCOM is analyzed under nonlinear load conditions in terms of harmonic mitigation and DC link voltage regulations. The objectives of the this paper are

a. Extracting the reference current control signal, using synchronous reference frame theory to compensate current harmonic at the PCC produced by nonlinear load.

b. Also Compensate source current harmonic and regulating the load voltage

c. Regulating the dc link voltage of voltage source inverter using with PI and Fuzzy logic controller and comparing the performance of DSTATCOM with separately using PI and Fuzzy logic controller.

d. Reactive power compensation and maintaining the constant voltage at PCC, under nonlinear load conditions.

e. Power factor correction.

\section{SYSTEM CONFIGURATION}

Figure 1 shows the system configuration of proposed Distribution static compensator (DSTATCOM) for the three phase three wire distribution system with nonlinear load. Three phase source voltage of $11 \mathrm{kv}$ is stepped down to $400 \mathrm{~V}$ by using $11 / 0.4 \mathrm{Kv}$ three phase transformers and connected to three phase nonlinear load. The connected nonlinear load introduces harmonic at the PCC. By Connecting DSTATCOM at the PCC harmonics elimination, load balancing with power factor correction and line voltage regulation at the bus are compensated. The DSTATCOM consist of three leg voltage source inverter using six IGBTs switches with interface inductor (Lf), dc link capacitor. The switching transients during DSTATCOM switching can be controlled by connecting a three phase capacitor ripple filter (Cf)

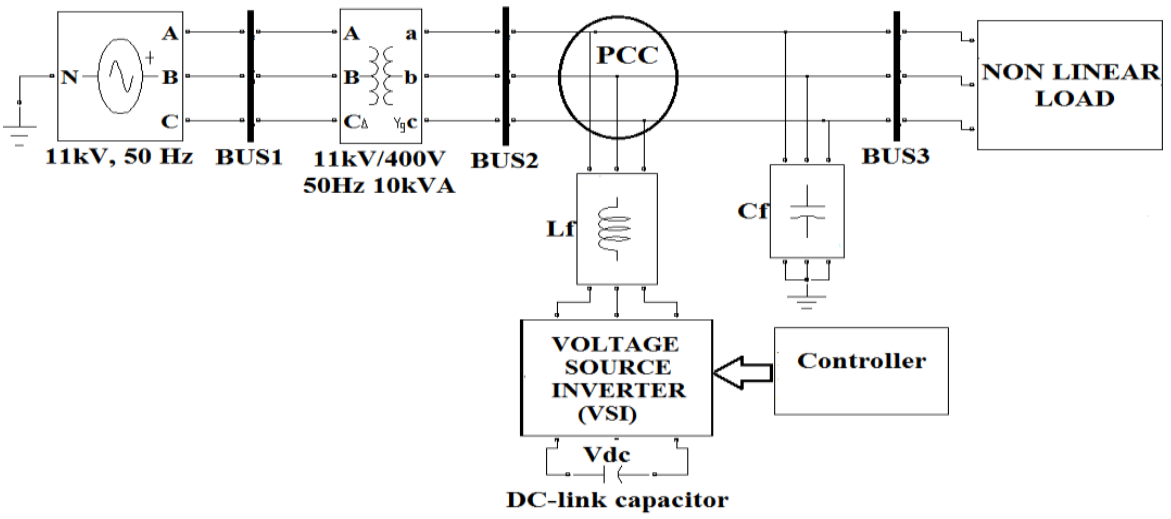

Figure 1. The system configuration

The modulated control switching signals to the VSI DSTATCOM is obtained from the synchronous reference control (SRF) strategy with hysteresis band control.

\section{SYSTEM CONFIGURATION}

The block diagram of the proposed SRF control algorithm is shown in Figure 2. The control algorithm is used for extracting the fundamental reference control signals to switching of VSI based DSTATCOM for harmonic and reactive power compensation during balanced nonlinear load condition.

The non linear load currents consist of active, reactive and harmonic currents in three phase system. In this, the reactive and harmonic components of currents are separated, for compensation. The separation includes converting the instantaneous three phase load currents into two phase stationary $\alpha-\beta-0$ axis using Clark's transformation equation. 
$\left[\begin{array}{l}i_{L 0} \\ i_{L \alpha} \\ i_{L \beta}\end{array}\right]=\sqrt{\frac{2}{3}}\left[\begin{array}{ccc}1 / \sqrt{2} & 1 / \sqrt{2} & 1 / \sqrt{2} \\ 1 & -1 / 2 & -1 / 2 \\ 0 & \sqrt{3} / 2 & -\sqrt{3} / 2\end{array}\right]\left[\begin{array}{l}i_{L a} \\ i_{L b} \\ i_{L c}\end{array}\right]$

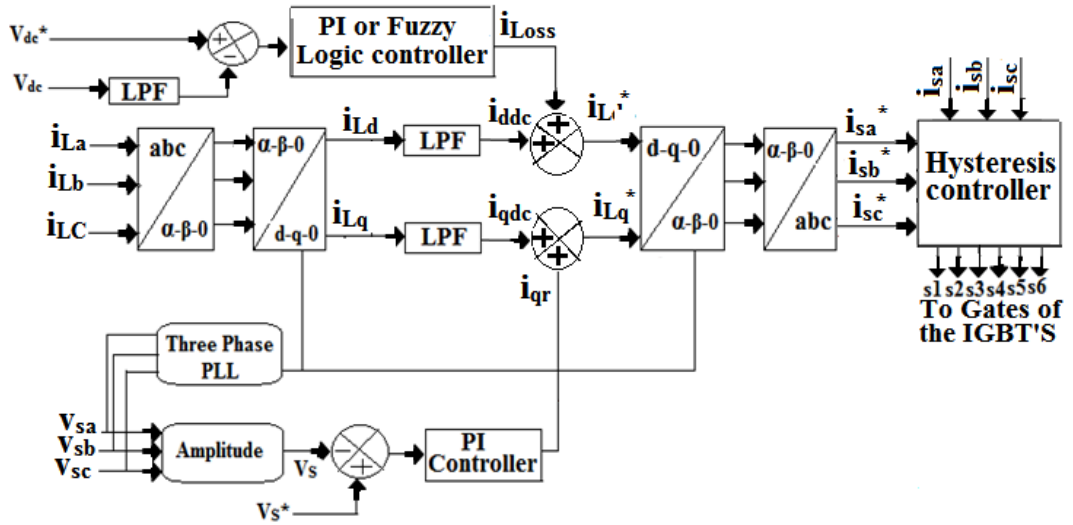

Figure 2. The block diagram of the proposed control algorithm

The stationery $\alpha-\beta-0$ current axis components are transformed into d-q- 0 (d-direct axis, q-quadrature axis components) rotating reference frame by using park transformation equation.

$\left[\begin{array}{l}i_{L 0} \\ i_{L d} \\ i_{L q}\end{array}\right]=\left[\begin{array}{ccc}1 & 0 & 0 \\ 0 & \cos \theta & \sin \theta \\ 0 & -\sin \theta & \cos \theta\end{array}\right]\left[\begin{array}{l}i_{L 0} \\ i_{L \alpha} \\ i_{L \beta}\end{array}\right]$

Here the $\theta$ is the transformation angle. The $\cos \theta$ and $\sin \theta$ is obtained from the three phase PLL block (phase locked loop) of voltage source for synchronization of voltage and current.

The $i_{\mathrm{Ld}}$ and $\mathrm{i}_{\mathrm{Lq}}$ current components are called instantaneous active and reactive load current components.

Each current component has an average value (dc component) and oscillating value (ac component) as given equation (3) \& equation (4).

$\mathrm{i}_{\mathrm{Ld}}=\mathrm{i}_{\mathrm{ddc}}+\mathrm{i}_{\mathrm{d} \text { ac }}$

$\mathrm{i}_{\mathrm{Lq}}=\mathrm{i}_{\mathrm{q} d c}+\mathrm{i}_{\mathrm{q}}$ ac

$\mathrm{i}_{d d c}$ and $\mathrm{i}_{q d c}$ are the average or $d c$ component of $\mathrm{i}_{L d}$ and

$\mathrm{i}_{\mathrm{d} a c}$ and $\mathrm{i}_{\mathrm{q}}$ ac are the oscillating or ac component of $\mathrm{i}_{\mathrm{Lq}}$ and

The oscillatory component (harmonic) appears like ripples. After eliminating the oscillatory current component by using Low pass filter, the average active and reactive current components are given in equation (5) \& equation (6).

$i L d=i d d c$

$\mathrm{iLq}=\mathrm{iq} \mathrm{dc}$

The output current of the PI or fuzzy logic controller is considered as loss current component $\left(\mathrm{i}_{\text {Loss }}\right)$ is added to the average active reference current component of $d$-axis in $d-q$ frame, In order to maintain the constant DC link voltage and to supply the losses in DSTATCOM. Then the active reference current component is

$\mathrm{iLd}^{*}=\mathrm{id} \mathrm{dc}+\mathrm{iloss}$

The direct axis reference current component $\left(\mathrm{i}_{\mathrm{Ld}}{ }^{*}\right)$ is used for compensation of harmonics and power factor. 
Similarly for regulating the voltage at the PCC, the source must need to deliver the reactive current $\left(\mathrm{i}_{\mathrm{qr}}\right)$, to be added to the average reactive reference component of current $\left(i_{\mathrm{q} d c}\right)$ of $q$-axis in $d-q$ frame same as direct current axis component. Then the resultant reactive reference current component is

$\mathrm{iLq}^{*}=\mathrm{iq} \mathrm{dc}+\mathrm{iqr}$

The reactive current $\left(\mathrm{i}_{\mathrm{qr}}\right)$ is obtained from the PI controller output, the input to the PI controller is obtained by subtracting the voltage amplitude Vs from the reference voltage Vs* and is fed to PI controller. Here the amplitude of the PCC voltage is given as

$\mathrm{Vs}=\sqrt{2 / 3\left(V_{s a}^{2}+V_{s b}^{2}+V_{s c}^{2}\right)}$

The PI controller output is given as

$\operatorname{Vqr}(\mathrm{n})=\operatorname{Vqr}(\mathrm{n}-1)+\operatorname{Kpq}(\operatorname{Vte}(\mathrm{n})-\operatorname{Vte}(\mathrm{n}-1))+\operatorname{Kiq} \operatorname{Vte}(\mathrm{n})$

Where $\operatorname{Vte}(\mathrm{n})=\mathrm{V} * \mathrm{~s}-\mathrm{Vs}(\mathrm{n})$ is the error between the reference $\left(\mathrm{V}^{*} \mathrm{~s}\right)$ and actual(Vs) terminal voltage amplitude at the nth sampling instant. Here Kpq and Kiq are the proportional and the integral gains of the PI controller. The reactive reference current component (iLq*) is used for ac voltage regulation and compensation of load reactive power. The Active and reactive reference current component (iLd*, iLq*) are transformed in to $\alpha-\beta-0$ frame obtained by using inverse park's Equation (11)

$\left[\begin{array}{l}\mathrm{i}_{\mathrm{s} 0}{ }^{*} \\ \mathrm{i}_{\mathrm{s} \alpha}{ }^{*} \\ \mathrm{i}_{\mathrm{s} \beta}{ }^{*}\end{array}\right]=\left[\begin{array}{ccc}1 & 0 & 0 \\ 0 & \cos \theta & -\sin \theta \\ 0 & \sin \theta & \cos \theta\end{array}\right]\left[\begin{array}{l}\mathrm{i}_{\mathrm{L} 0}{ }^{*} \\ \mathrm{i}_{\mathrm{Ld}}{ }^{*} \\ \mathrm{i}_{\mathrm{Lq}}{ }^{*}\end{array}\right]$

The reference currents from the Inverse Park's are transformed into three phase reference current (a-b-c) by using inverse Clark's Equation (11).

$\left[\begin{array}{l}i_{s a}{ }^{*} \\ i_{s b}{ }^{*} \\ i_{s c}{ }^{*}\end{array}\right]=\sqrt{\frac{2}{3}}\left[\begin{array}{ccc}0 & 1 & 0 \\ 0 & -1 / 2 & \sqrt{3} / 2 \\ 0 & -1 / 2 & -\sqrt{3} / 2\end{array}\right]\left[\begin{array}{c}\mathrm{i}_{\mathrm{s} 0}{ }^{*} \\ \mathrm{i}_{\mathrm{s} \alpha}{ }^{*} \\ \mathrm{i}_{\mathrm{s} \beta}{ }^{*}\end{array}\right]$

The obtained three phase reference currents $\left(\mathrm{i}_{\mathrm{sa}}{ }^{*}, \mathrm{i}_{\mathrm{sb}}{ }^{*}, \mathrm{i}_{\mathrm{sc}}{ }^{*}\right)$ are compared with the actual compensating filter currents in hysteresis band controller for better switching of VSI of IGBT's. The main advantage of this hysteresis band controller is easy implementation, better stability, faster response as compared to the other controller like carrier based, bead beat and feed forward etc [17]. The main disadvantage of the carrier based controller is variable switching frequency which may causes stress on the switching devices as compared to the hysteresis band controller

\section{DC LINK VOLTAGE REGULATION}

The quality and performance of DSTATCOM depends upon the generation of the compensating reference current, In which dc link voltage regulation is the key factor. According to requirement of compensating current, the dc-link voltage $(\mathrm{Vdc})$ is either increases or decreases. For proper operation of VSI the dc side of the inverter should kept constant at a particular reference value. The filter and switching power losses of VSI overcome by maintaining constant dc-link voltage. In order to regulating or maintaining dc-link voltage constant a controller is needed to add the average active current component $\left(\mathrm{i}_{\mathrm{dcc}}\right)$ of $\mathrm{d}$-axis in rotating frame theory. Here the following two controllers have been added and compared.

a. PI controller

b. Fuzzy logic controller

\subsection{PI Controller}

Figure 3 shows the PI controller block diagram. It is the internal structure of the control circuit. The source must need to deliver the loss reference component of current ( $\left.i_{\text {LOSS }}\right)$ along with active reference current component $\left(i_{\mathrm{Ld}}\right)$, for the supplying of losses in the DSTATCOM and filter. The loss reference 
component of current ( $\mathrm{i}_{\text {LOsS }}$ ) is extracted, by comparing the reference dc bus voltage $\mathrm{V}_{\mathrm{dc} * \text { With the actual dc }}$ bus voltage $\mathrm{V}_{\mathrm{dc}}$ of VSI at the $\mathrm{n}^{\text {th }}$ sampling instant.

$\operatorname{Vde}(\mathrm{n})=\operatorname{Vdc} *(\mathrm{n})-\operatorname{Vdc}(\mathrm{n})$

The compared error signal $\mathrm{V}_{\mathrm{de}(\mathrm{n})}$ is processed through a PI controller to compute the loss component ( $\left.\mathrm{i}_{\text {Loss }}\right)$ at $\mathrm{n}^{\text {th }}$ sampling instant is expressed as

$i \operatorname{Loss}(n)=\operatorname{iloss}(n-1)+\operatorname{kpd}(\operatorname{Vde}(n)-\operatorname{Vde}(n-1))+\operatorname{kid} \operatorname{Vde}(n)$

Here the $\mathrm{k}_{\mathrm{pd}}$ and $\mathrm{k}_{\mathrm{id}}$ are the proportional and integral gains of PI controller. The values given $\mathrm{k}_{\mathrm{pd}}=$ $0.6, \mathrm{k}_{\mathrm{id}}=0.007$. the output of the PI controller is the loss reference component ( $\mathrm{i}_{\text {Loss }}$ ) of the DSTSTCOM. The loss reference current component $\left(i_{\text {loss }}\right.$ is added to the average active reference component $\left(i_{L d}\right)$ for regulating the active reference component of current $\left(\mathrm{i}_{\mathrm{Ld}^{*}}\right)$.The estimated reference current component is compared with the actual compensating filter currents in hysteresis band controller for better switching of VSI of IGBT's

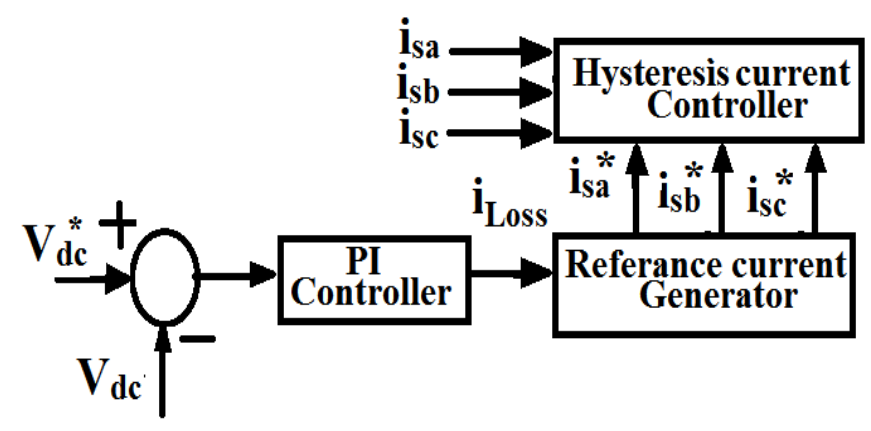

Figure 3. Block diagram of PI controller

\subsection{Fuzzy logic controller}

Figure 4(a) shows the proposed internal structure of Fuzzy logic controller and the Figure 4(b) shows the proposed control block diagram of the fuzzy logic controller. The actual dc link capacitor voltage is compared with the reference dc voltage. The error signal is processed through the fuzzy logic controller, reference.

For supplying the active power to compensate the losses in VSI and maintain the dc-link voltage constant, the fuzzy logic controller output is added to the fundamental active current component and the resultant compensating current are compared with the actual sensed compensating filter current in hysteresis band, which gives error signal. The error signal decides the operation of the VSI.

FIS consists of Fuzzy Inference System (FIS) Editor, Membership Function Editor, Rule Editor, and Rule Viewer, Surface Viewer and defuzzification [18 -21].

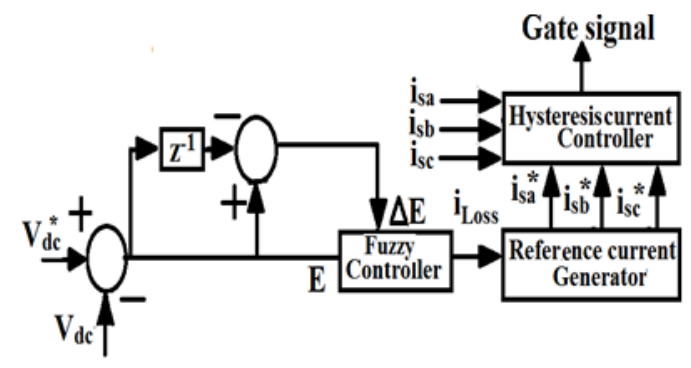

Figure 4(a). Block diagram of Fuzzy logic controller

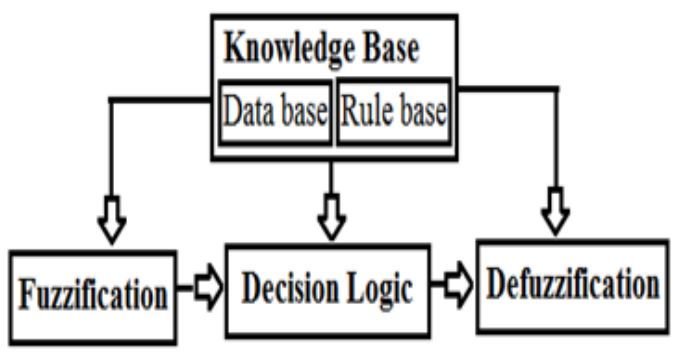

Figure 4(b).The proposed control block diagram

In this paper the fuzzy interface system we have designed as

1. No of inputs and outputs (2 inputs and 1output).

2. No of membership functions (seven). 
3. Type of implication (Mamdani max-min operation).

4. Type of defuzzification method (centroid of area method).

5. No. of rules (49 rules).

6. Input membership function (Gaussian)

7. Input membership function (triangular)

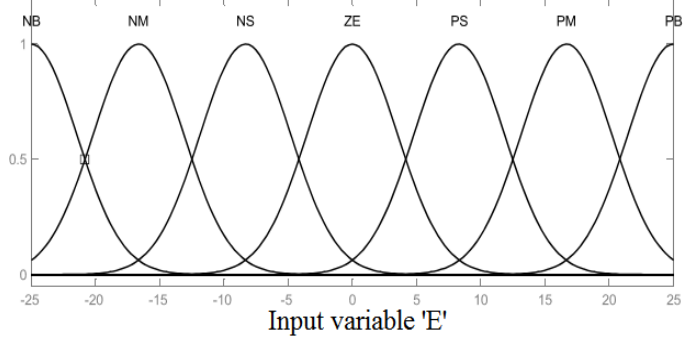

Figure 4(c). Gaussian membership function for input variable

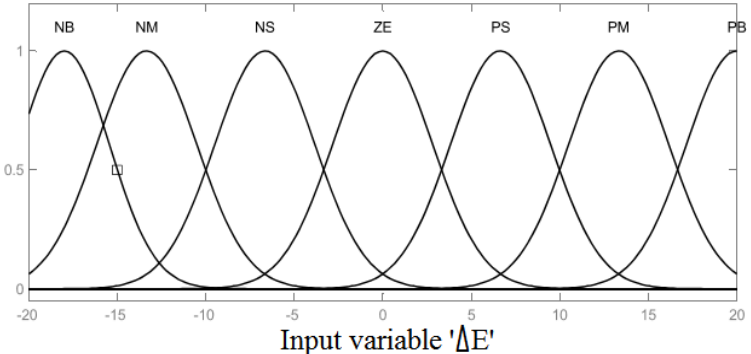

Figure-4(d). Gaussian membership function for change in input variable

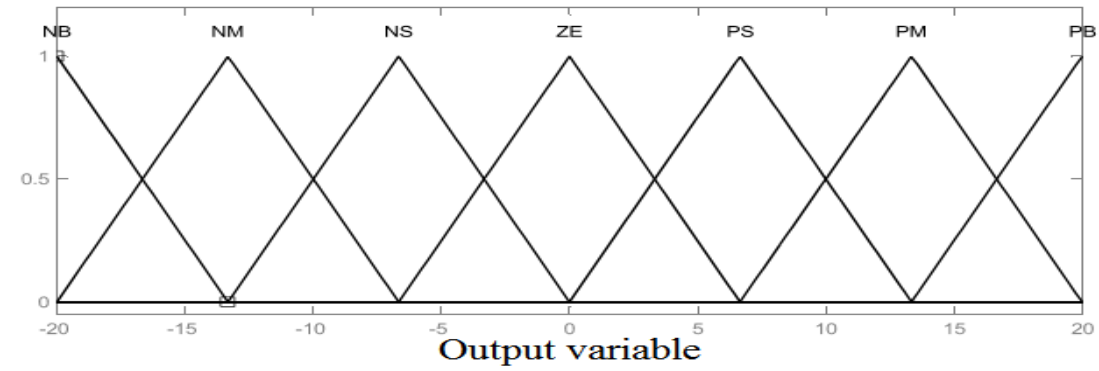

Figure 4(e). Triangular output variable membership function

The decision rule table relating to the input to the output fuzzy sets as shown in Table-I.

Table 1. Decision rule table

\begin{tabular}{clllllll}
\hline E / $\Delta$ E & NB & NM & NS & ZE & PS & PM & PB \\
\hline NB & NB & NB & NB & NB & NM & NS & ZE \\
NM & NB & NB & NB & NM & NS & ZE & PS \\
NS & NB & NB & NM & NS & ZE & PS & PM \\
ZE & NB & NM & NS & ZE & PS & PM & PB \\
PS & NM & NS & ZE & PS & PM & PB & PB \\
PM & NS & ZE & PS & PM & PB & PB & PB \\
PB & ZE & PS & PM & PB & PB & PB & PB \\
\hline
\end{tabular}

For the $\mathrm{N}$ linguistic variables for each of the input and output there are $\mathrm{N}^{2}$ possible combinations resulting into any of $\mathrm{M}$ values for the decision variables. All the possible combination is called states. The resulting fuzzy matrix are $\left(\mathrm{N}^{2} * \mathrm{M}\right)=49$. All this 49 states are control variables of membership functions.

In defuzzification the fuzzy set output produced according to decision logic (linguistic variables) is transformed into crisp values of output. For this defuzzification 'centroid' method is used. The crisp output value expressed in 'centroid' is given as

$u=\frac{\sum_{q=1}^{7} \mu_{\Delta \mu q} X_{G q}}{\sum_{q=1}^{7} \mu_{\Delta \mu q}}$ 
Where $\mathrm{X}_{\mathrm{Gq}}$ is the centre of membership function, $\mu_{\Delta \mu \mathrm{q}}$ is the max of all rules that give the same decision from the both the controller the fuzzy logic controller provided the better response and improve the behaviour of DSTATCOM.

\section{RESULTS AND DISCUSSION}

The proposed DSTATCOM model is implemented in MATLAB/SIMULINK software using synchronous reference frame control algorithm with PI and FUZZY logic controller. The model is verified under nonlinear load condition. The proposed model is used for harmonic compensation, power factor correction and voltage regulation at the PCC. The simulation results with PI and FUZZY logic controller is also compared. The simulation period is taken from $0.2 \mathrm{~s}$ to $0.3 \mathrm{~s}$ for the better observation. The performance of DSTATCOM is observed for the following cases
a. Non Linear load without DSTATCOM
b. DSTATCOM with PI Controller
c. DSTATCOM with Fuzzy logic controller
d. THD analysis
e. Comparison of DC-link voltage (PI \&Fuzzy logic controller).

\subsection{Non Linear load without DSTATCOM}

The When nonlinear load is connected to the proposed distribution system causes, harmonic in source current (Bus-1) as shown in Figure- 5(b). The nonlinear load also introduces harmonics in the voltage and current wave form at the PCC (bus-2).is shown in Figure-5(c) \& 5(d). The harmonics effects the loads connected the PCC. Figure-5(e) \&5(f) shows the load voltage and load current. The per phase representation of the current at the PCC is shown in Figure-5(g).
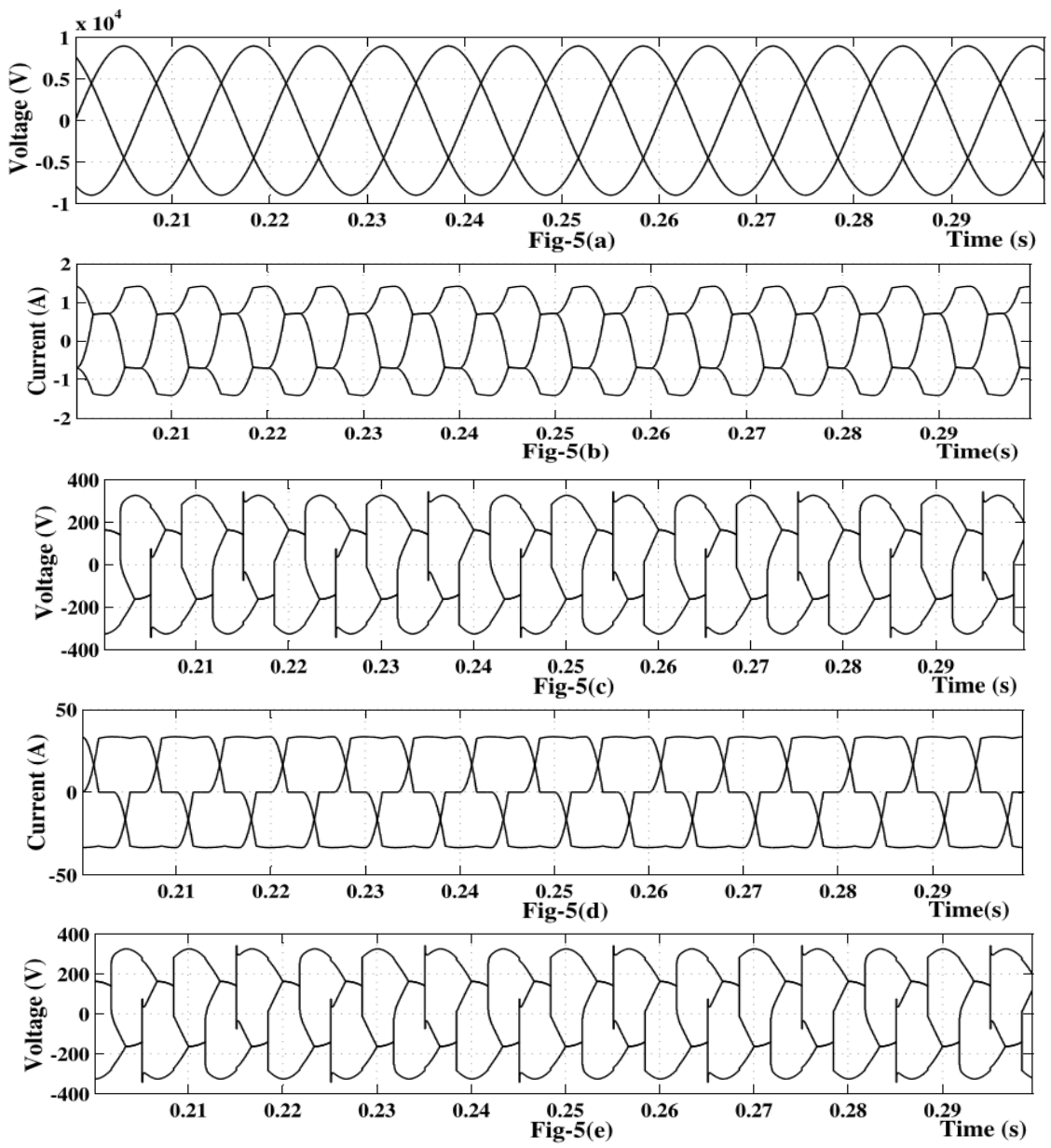

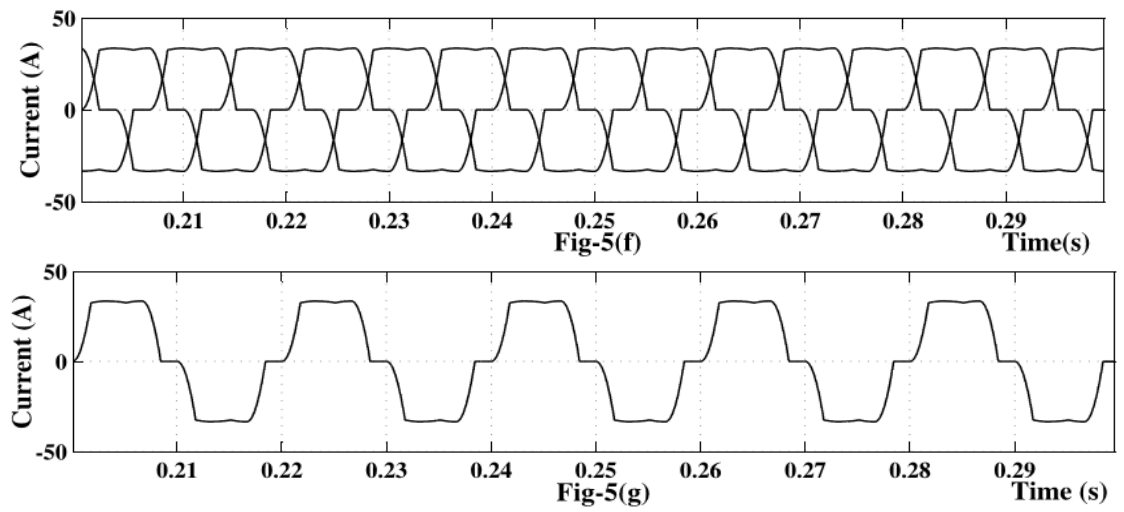

Figure 5 (a)Source voltage wave form, (b). Source current wave form, (c).voltage waveform at the PCC (Bus-2), (d). Current waveform at the PCC (Bus-2), (e).Load voltage wave form, (f).Load current wave form,

(g). Per phase representation of PCC current wave form, under nonlinear load without D-STATCOM

\subsection{D-STATCOM with PI Controller}

When SRF controlled D-STATCOM is connected at the PCC, the D-STATCOM is injecting the required amount of reactive power for compensation of current and voltage harmonics at the PCC and it also compensating the source current harmonics. The DC-link voltage is regulating with PI controller. The compensated source and PCC current waveforms as shown in Figure-6(b) \& 6(c). Using R-C filter load and PCC Voltage is compensated. Figure-6(d) shows the compensated and regulated voltage waveform at the PCC. Load voltage is also compensated as shown in Figure-6(e). Figure 6(f) shows the load current waveform. The DC-link voltage, per phase representation of the current wave form wave form as shown in Figure-6(g) \& 6(h).
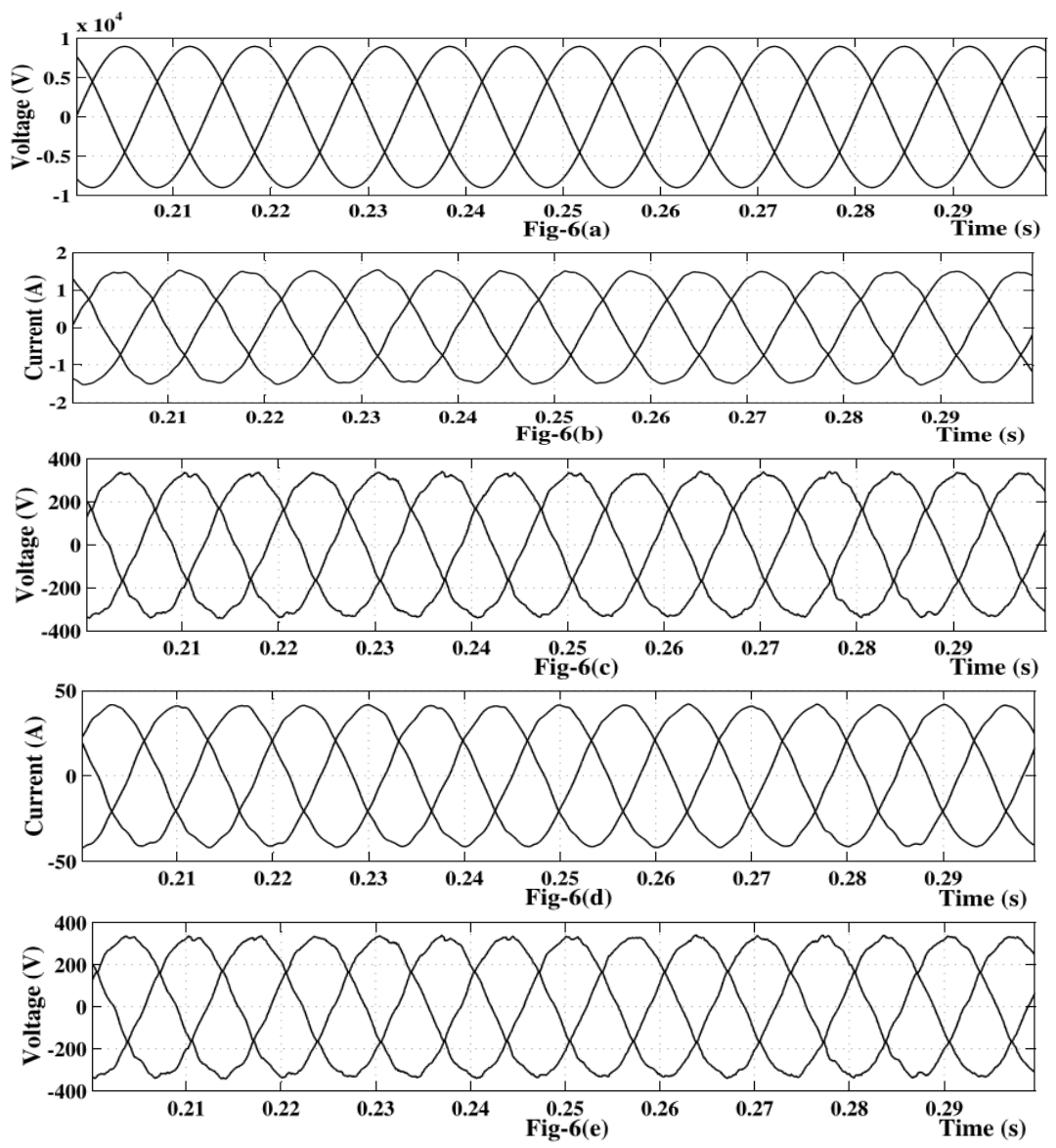

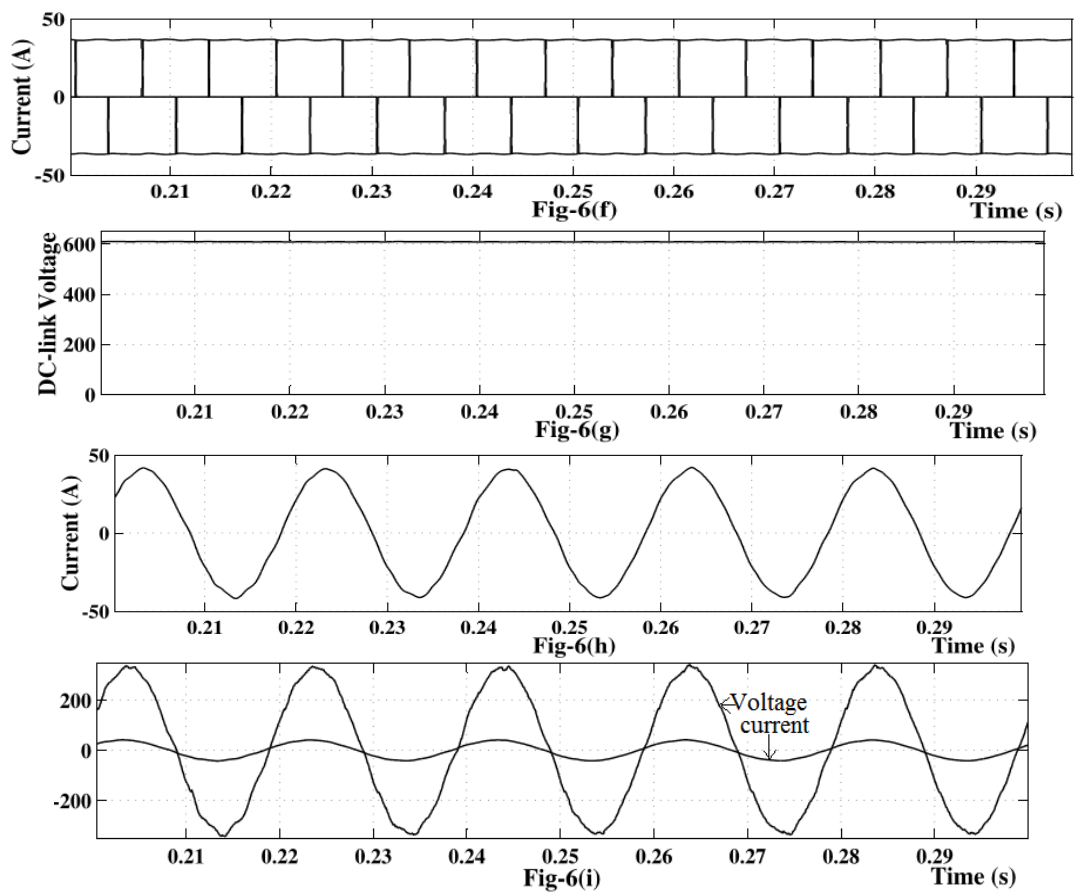

Figure 6 (a)Source voltage wave form, (b). Source current wave form, (c).voltage waveform at the PCC (Bus-2), (d). Current waveform at the PCC (Bus-2), (e).Load voltage wave form, (f).Load current wave form, (g).DC-link voltage form, (h). Per phase representation of current wave form at the PCC, (i). Voltage and current wave form, under nonlinear load with PI controlled D-STATCOM

\subsection{D-STATCOM with Fuzzy logic controller}

The SRF controlled D-STATCOM is connected at the PCC, the D-STATCOM is injecting the required amount of reactive power for compensation of current and voltage harmonics at the PCC and it also compensating the source current harmonics. The DC-link voltage is regulating with fuzzy logic controller. By comparing with PI controller the fuzzy logic controller provided better harmonic and reactive power compensation and its corresponding waveforms as shown in Figure-9.The compensated source and PCC current waveforms as shown in Figure-7(b) \& 7(c). Using R-C filter load and PCC Voltage is compensated. Figure-7(d) shows the compensated and regulated voltage waveform at the PCC. Load voltage is also compensated as shown in Figure-7(e). Figure 7(f) shows the load current waveform. The DC-link voltage, per phase representation of the current wave form wave form as shown in Figure-7(g) \& 7(h).
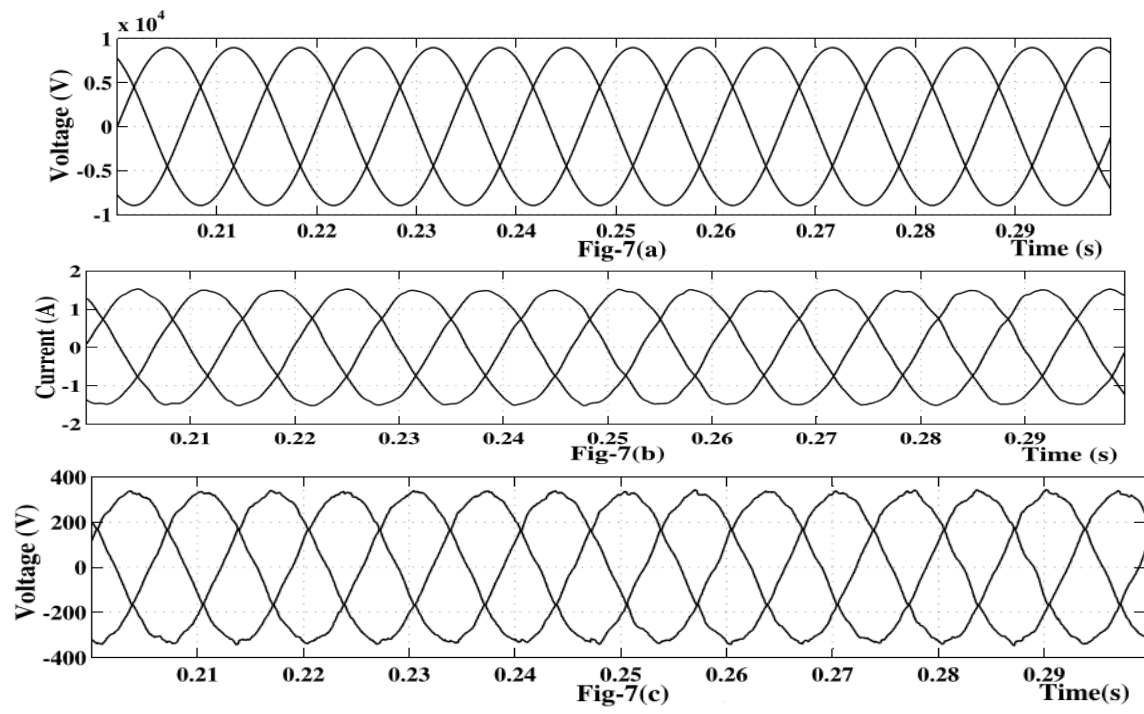

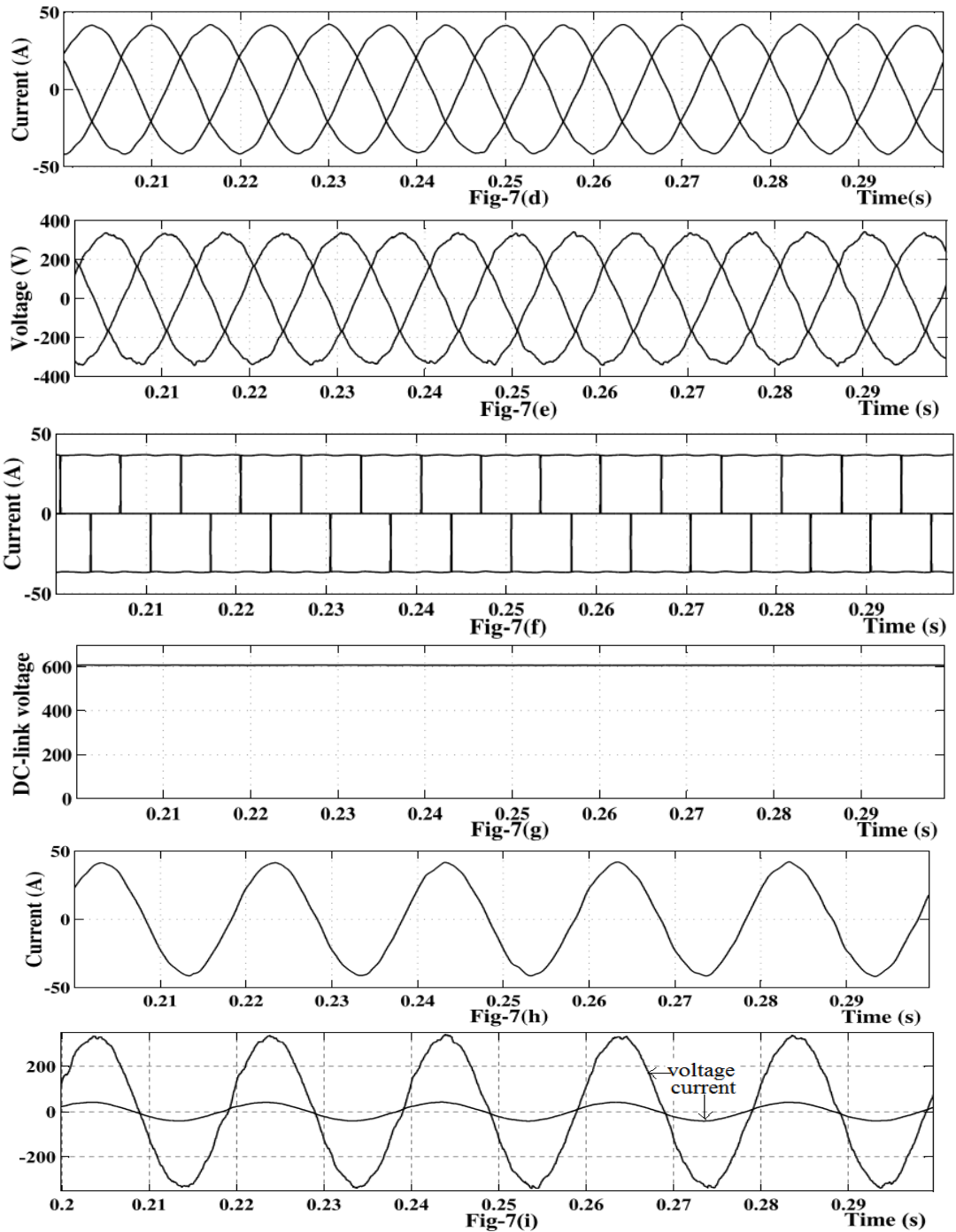

Figure 7 (a)Source voltage wave form, (b). Source current wave form, (c).voltage waveform at the PCC (Bus-2), (d). Current waveform at the PCC (Bus-2), (e).Load voltage wave form, (f).Load current wave form, (g).DC-link voltage form, (h). Single phase representation of current wave form at the PCC, (i). Voltage and current wave form, with Fuzzy logic controlled D-STATCOM

\subsection{Total Harmonic Distortion analysis}

The total harmonic distortion at the source PCC and PCC for the proposed system with and without DSTATCOM is discussed here. And also the analysis is done with PI and Fuzzy logic controller.

\subsubsection{Non Linear load without DSTATCOM}

The total harmonic distortion of the system by connecting nonlinear load without DSTATCOM as shown in Figure 8. The Current and voltage harmonic distortion at the PCC is observed that $19.20 \%$ and $18.39 \%$ as shown in Figure 8(a) \&8(b). The source current harmonic distortion $19.11 \%$ as shown in Figure8(c). 


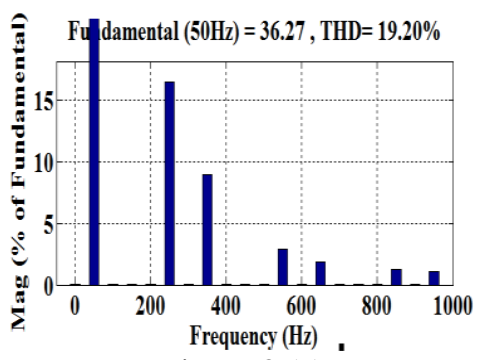

Figure 8 (a)

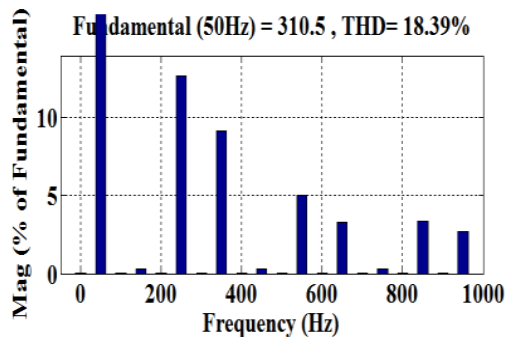

Figure 8 (b)

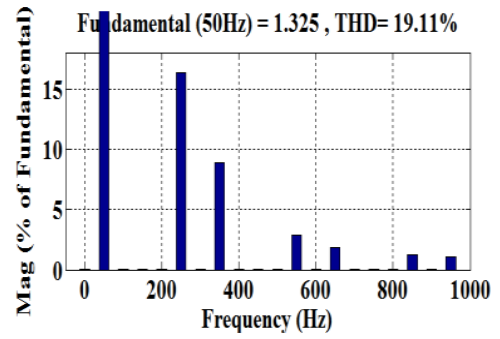

Figure 8 (c)

Figure-8. (a) Current THD at PCC, (b). Voltage THD at PCC, (c). Source current THD (BUS-1)

\subsubsection{DSTATCOM with PI Controller}

BY Connecting DSTATCOM to the proposed system, the current and voltage harmonics distortion at the PCC is reduced to $2.41 \%$ and $2.60 \%$ as shown in Figure 9(a) \& 9(b).the source current harmonic distortion is reduced to $2.13 \%$, as shown in Figure 9(c).

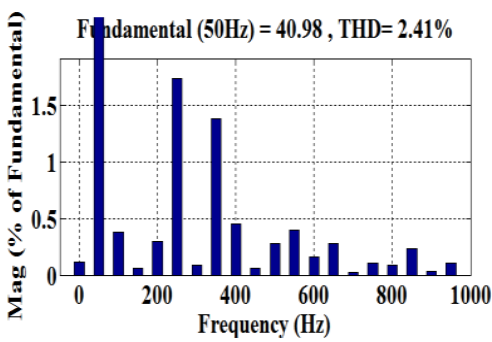

Figure 9 (a)

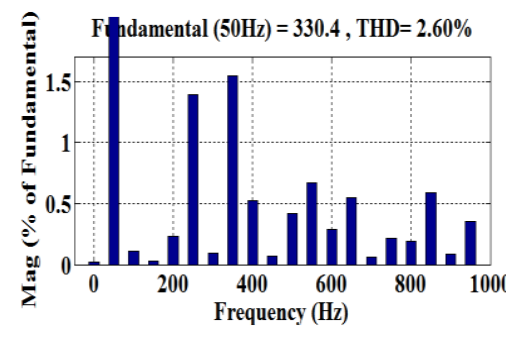

Figure 9 (b)

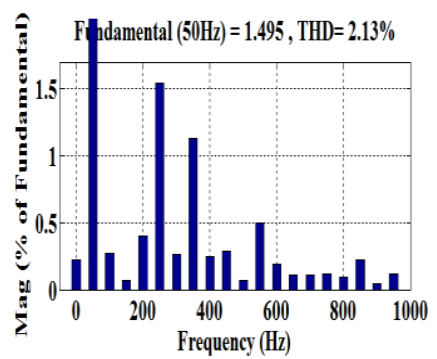

Figure 9 (c)

Figure 9 (a) Current THD at PCC, (b). Voltage THD at PCC, (c). Source current THD (BUS-1)

\subsubsection{DSTATCOM with Fuzzy logic Controller}

With fuzzy logic controlled DSTATCOM the current and voltage harmonic distortion at the PCC is reduced to $1.49 \%$ and $2.07 \%$ as shown in Figure 10 (a) \& 10 (b). And the source current harmonic distortion is reduced to $1.41 \%$, as shown in Figure 10(c).

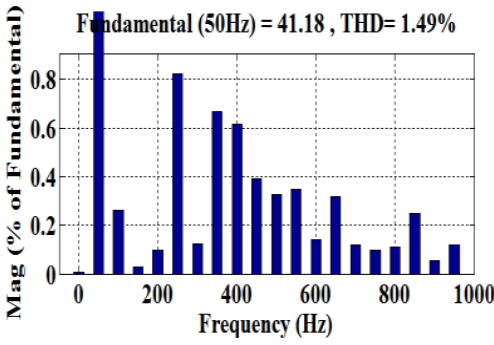

Figure 10 (a)

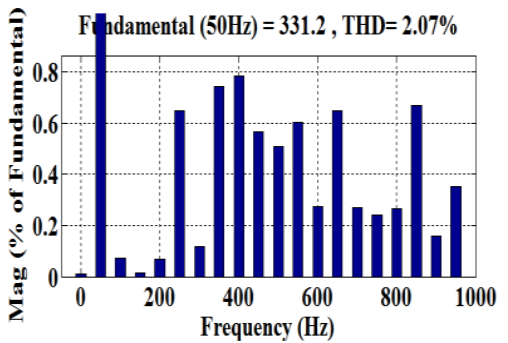

Figure 10 (b)

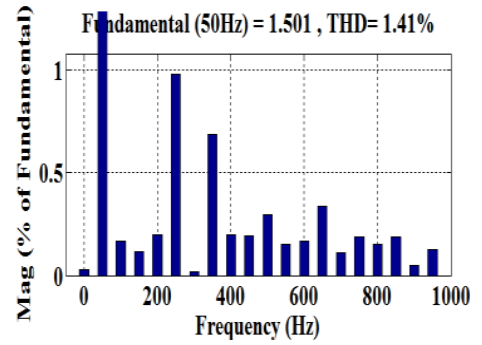

Figure $10(\mathrm{c})$

Figure 10. (a) Current THD at PCC, (b). Voltage THD at PCC, (c). Source current THD (BUS-1)

By observing from the above total harmonic distraction analysis the fuzzy logic controller DSTATCOM is providing better harmonic distortion as compare to the PI controller DSTATCOM. 


\subsection{Comparison of DC-link voltage}

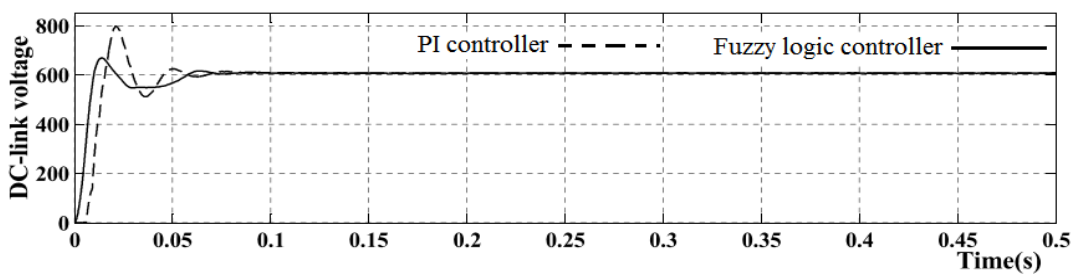

Figure-11. Comparison of DC-link voltage variation with PI and Fuzzy logic controller

The dc-link voltage comparison with PI and Fuzzy logic controller as shown in Figure-11. It is observed that the transient time and settling of fuzzy logic controller is better as compare to the PI controller.

\section{CONCLUSIONS}

In this paper, the performance of VSI based DSTATCOM has been analyzed using the synchronous reference frame control algorithm for the compensation of reactive power, harmonic and load balancing in three phase three wire nonlinear load distribution system. The control algorithm used here is simple and easy to implement and found be satisfactory for nonlinear load distribution system. The simulation results for the proposed system is analysed and compared separately with PI and FUZZY logic controller. The dc bus voltage is maintained constant for under all distribuances conditions for both controllers. The both controllers provide good compensation, but fuzzy logic controller providing superior performance under nonlinear load conditions. The simulation results are obtained in MATLAB/SIMULINK software shows that the fuzzy logic controlled DSTATCOM provides better system dynamic response and hence it improves transient behaviour and power quality as compare to the PI controlled DSTATCOM.

\section{REFERENCES}

[1] B. Bose, "Global energy scenario and impact of power electronics in 21st. century," IEEE Trans. Ind. Electron., vol. 60, no. 7, pp. 2638-2651, July 2013.

[2] Phipps JK, Nelson JP, Sen PK., "Power quality and harmonic distortion on distribution systems," IEEE Trans Ind Appl, vol. 30, pp. 476-84, 1994.

[3] Hive S, Chatterjee K, Fernandes BG, "VAr compensation and elimination harmonics in three-phase four-wire system based on unified constant frequency integration control." In: IEEE 11th international conference on harmonics and quality of, power, p. 647-51, 2004.

[4] George M, Basu KP. "Modelling and control of three-phase shunt active power filter." Am J Appl Sci 2008, vol. 5, no. 5, pp. 1064-70, 2008.

[5] Acha E, Agelids V, Anaya-Lara O, Miller T. Power electronic control in electric systems. 1st ed. Oxford: Newness Power engineering series; 2002.

[6] Akagi H, Watanabe EH, Aredes M. Instantaneous power theory and applications to power conditioning. New Jersey, USA: John Wiley \& Sons; 2007.

[7] Fuchs EwaldF, Mausoum Mohammad AS. Power Quality in Power Systems and Electrical Machines. London, UK: Elsevier Academic Press; 2008.

[8] Jayahar D, Ranihemamalini R, Rathnakannan K. Design and implementation of Single Phase AC-DC BuckBoostConverter for power factor correction and Harmonic Elimination, International Journal of Power Electronics and Drive Systems. 2016; 7(3): 1004-1011.

[9] Singh B, Chandra A, Al-Haddad K. Reactive power compensation and load balancing in electric power distribution systems. Int J Electr Power Energy Syst 1998; 20:375-81.Aug.

[10] A. Ghosh and Gerard Ledwich, "Power Quality Enhancement Using Custon Power Devices", Kluwer Academic Publishers, USA, 2002April 1955.

[11] Jayaprakash P, Singh B, Kothari D. Three-phase 4-wire dstatcom based on h-bridge vsc with a star/hexagon transformer for power quality improvement.In: IEEE region 10 and the third international conference on industrial and information systems, 2008. ICIIS 2008; 2008. p. 1-6.

[12] Mikkili Suresh, Panda AK. Real-time implementation of PI and fuzzy logic controllers based Shunt active filter control strategies for power quality improvement. Int J Electr Power Energy Syst 2012; 43(1):1114-26.

[13] Soares Vasco, Verdelho Pedro, Marques Gil D. An instantaneous active and reactive current component method for active filters. IEEE Trans Power Electron 2000;15(4):660-9.

Int J Pow Elec \& Dri Syst, Vol. 9, No. 2, June 2018 : 465 - 477 
[14] Mikkili Suresh, Panda AK. PI and fuzzy logic controller based 3-phase 4-wire Shunt active filter for mitigation of Current harmonics with Id-Iq control strategy. J Power Electron (JPE) 2011; 11(6):914-21.

[15] Zadeh LA. Fuzzy Sets Information and Control 1965; 8: 338-353.

[16] Mamdani EH. Application of fuzzy logic to appropriate reasoning using linguistic synthesis. IEEE Trans Comput 1997;26 (12):1182-91.

[17] L Malesani, P. Tenti, "A Novel Hysteresis Control Method for Current-Controlled VSI PWM Inverters with Constant Modulation Frequency", IEEE IAS-87, pp. 851-855, 1987

[18] Pedrycz W, Gomide F. The design of fuzzy sets. Fuzzy systems engineering: toward human-centric computing. Wiley-IEEE Press eBook Chapters; 2007. p. 67-100.

[19] Runkler TA. Selection of appropriate defuzzification methods using application specific properties. IEEE Trans Fuzzy Syst 1997;5 (1):72-9.

[20] Jang J-SR, Sun C-T, Mizutani E. Neuro-fuzzy and soft computing. Englewood Cliffs, NJ: Prentice-Hall; 1997.

[21] Lalitha Kameswari y, Chandra Sekhar o. "Fuzzy Logic Controlled Harmonic Suppressor in Cascaded Multilevel Inverter", International Journal of Power Electronics and Drive System (IJPEDS), ISSN: 2088-8694, Vol. 7, No. 2, pp. 303 310, June 2016.

\section{Appendix A}

Supply voltage

Step-down Transformer

Nonlinear load

DC-link capacitance

DC-link voltage

Ripple filter

DC-bus PI controller

AC-bus PI controller
$11 \mathrm{Kv}$

$11 / 0.4 \mathrm{Kv}$

Three phase bridge rectifier with $\mathrm{R}-\mathrm{L}$ load. $\mathrm{R}=15 \Omega, \mathrm{L}=60 \mathrm{mH}$ 3000Uf

$600 \mathrm{~V}$

$\mathrm{L}_{\mathrm{f}}=0.3 \mathrm{mf}, \mathrm{C}_{\mathrm{f}}=30 \mathrm{uf}$

$\mathrm{K}_{\mathrm{p} 1}=0.667, \mathrm{~K}_{\mathrm{p} 2}=0.0078$

$\mathrm{K}_{\mathrm{p} 1}=6.07, \quad \mathrm{~K}_{\mathrm{p} 2}=0.067$ 